\section{Flipped Laboratory Sessions using Video Vignette and Active Learning: A Hybrid Approach for Online Teaching}

Sir,

Due to increased risk of COVID-19 infection, institutes such as schools, colleges and universities, were advised to close down; and this unprecedented situation led us to remote learning and online teaching. During these difficult times, technology has helped reducing the hurdles; and different instructional strategies were used. Flipped-classroom is one of effective teaching strategies that has been used by many educators to promote active learning, improve outcomes, enhance student engagement and manage time and resources. ${ }^{1}$ In flipped-classroom teaching, the core material is presented before the session to the students to familiarise them with the topic (via video recording, discussion forums). The lecture session is then used to explore and consolidate understanding through questions and challenges, followed by active laboratory experiment. ${ }^{1}$ In a hybrid or virtual flipped class room, all asynchronous process remain the same with the exception of the active laboratory sessions, which are conducted live by the facilitators under simulated conditions; whereas, the students are in attendance virtually, via audio conferencing, video conferencing, web chats etc. $^{2}$

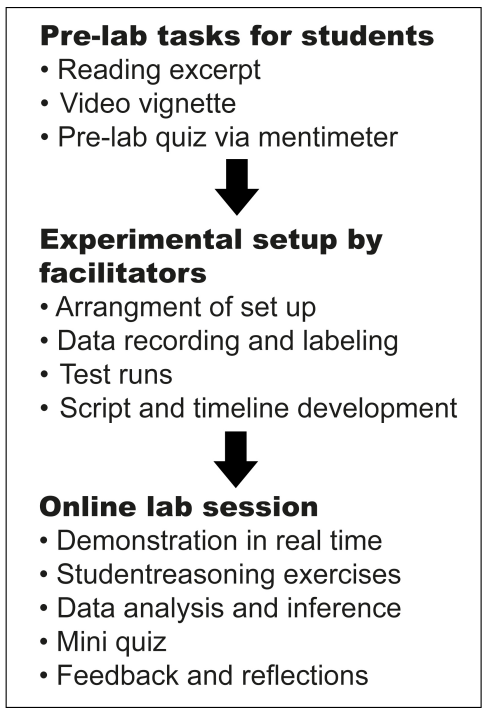

Figure 1: Flow of events in the flipped laboratory session.

The online instructional methods, which no doubt are an efficient tool for learning, have some challenges such as limited non-verbal communication, compromised students-teachers interactions, narrow accessibility of materials and constrained time management that needs to be addressed while designing the lesson plan. ${ }^{3}$ Our group has successfully implemented the flipped learning method in undergraduate medical education; ${ }^{4}$ and recent research has also supported flipped classroom to be an ideal model for pre-clinical medical education. ${ }^{5}$ Based on these aspects, an interactive flipped laboratory session, entitled basal metabolic rate and thermogenic effect of food, was conducted for undergraduate medical students, in a way that could convey all essential information and give some data to apply the knowledge gained (Figure 1).

To do this, two physiology subject experts, along with a laboratory staff, developed reading material and a short introductory video, covering the basics of BMR and factors affecting/regulating it.

These resources were shared with the students through the universities' virtual learning platform-moodle as pre- laboratory asynchronous activity one week before the scheduled virtual synchronous session. The asynchronous activity was supplemented by a self-paced formative assessment, conducted through mentimeter. ${ }^{6}$ In the virtual synchronous session, a complete BMR setup, using Power Lab and Lab Station software (AD instruments), was used to demonstrate how expired air can be collected into a Douglas bag, how BMR can be calculated from the fraction of expired oxygen and the difference between energy metabolism after taking protein and carbohydrate diet can be calculated. During the virtual laboratory session, students were not only doing reasoning exercises, but were also making inferences on simulated data sets. The session was facilitated by the same subject experts, to guide students on application of knowledge in a dynamic and interactive way, based on the content, personal experiences or research-based evidence.

Feedback from students post-session revealed that the strategy substantiated student learning, and helped clarify students' misconceptions on the spot, thus increasing students' interaction and engagement. Video vignette was found to be an excellent tool, which provided the students a chance of understanding the methodology over and over again. Facilitators also found it a useful and effective way of teaching practical session virtually. A well-designed pre-lab test question or virtual preparatory session helped students contextualise laboratory objectives, supporting the concrete experience stage. Additionally, the use of the virtual laboratories provides an ideal framework for inducing reflections during the preparation session. According to Kolb's model, these reflected the conceptualisation and learning already acquired during the preparation for the laboratories. In future, we look forward to work on implementing this hybrid model to other laboratories across disciplines, and improving this teaching strategy, based on student feedback.

\section{CONFLICT OF INTEREST:}

The authors declared no conflict of interest.

\section{AUTHORS' CONTRIBUTION:}

SF: interpretation, drafting and final approval. 
RR, SSF: Conception, design, implementation, interpretation, analysis, critical review and final approval of manuscript.

\section{REFERENCES}

1. Betihavas $V$, Bridgman $H$, Kornhaber $R$, Cross $M$. The evidence for 'flipping out': A systematic review of the flipped classroom in nursing education. Nurse Educ Today 2016; 38:15-21. doi: 10.1016/j.nedt.2015.12.010.

2. Finkelstein JE. Learning in real time: Synchronous teaching and learning online: John Wiley \& Sons; 2006.

3. Bergmann J, Sams A. Flip your classroom: Reach every student in every class every day: International society for technology in education; 2012.

4. Fatima SS, Arain FM, Enam SA. Flipped classroom instructional approach in undergraduate medical education. Pak J Med Sci 2017; 33(6):1424-8. doi: 10.12669/ pjms.336.13699.

5. Street SE, Gilliland KO, McNeil C, Royal K. The flipped classroom improved medical student performance and satisfaction in a pre-clinical physiology course. Med Sci Educator 2015; 25(1):35-43.

6. Iona, John. "Mentimeter." School Librarian, vol. 66, no. 3, Autumn 2018, p. 153. Accessed 12 Feb. 2021. MLA 8th Edition; APA 7th Edition

Sabah Farhat, Rehana Rehman and Syeda Sadia Fatima Department of Biological and Biomedical Sciences, The Aga Khan University Hospital, Karachi, Pakistan

Correspondence to: Dr. Syeda Sadia Fatima, Department of Biological and Biomedical Sciences, The Aga Khan University Hospital, Karachi, Pakistan

E-mail: sadia.fatima@aku.edu

Received: November 05, 2020; Revised: February 21, 2021; Accepted: February 25, 2021

DOI: https://doi.org/10.29271/jcpsp.2021.09.1139 